\title{
ASO Author Reflections: Defining Oligometastatic Recurrence in Biliary Tract Cancer
}

\author{
Koshiro Morino, MD, Tomoaki Yoh, MD, and Satoru Seo, MD \\ Department of Surgery, Graduate School of Medicine, Kyoto University, Kyoto, Japan
}

\section{PAST}

Oligometastasis and oligometastatic recurrence can be successfully managed using locoregional therapy (LT), such as repeat surgical resection or radiotherapy, and are emerging topics in oncology research. ${ }^{1,2}$ However, these concepts have been ill-defined in biliary tract cancer (BTC). While the standard treatment for recurrent BTC is systemic chemotherapy offering approximately only 12 months, ${ }^{3}$ implementation of LT was reported to be associated with a benefit for selected patients with recurrent BTC. ${ }^{4,5}$ The present study was designed to identify patients who benefitted the most from LT for recurrent BTC, which might help to generate a clinically relevant definition of "oligometastatic recurrence" in BTC.

\section{PRESENT}

Our study evaluated 232 consecutive patients with recurrent BTC who initially underwent curative surgical resection between 1996 and 2015. ${ }^{6}$ Of these, 60 patients underwent LT and 172 patients did not. The multivariate Cox model identified carbohydrate antigen 19-9 levels $>50 \mathrm{U} / \mathrm{mL}$, multiorgan recurrence, tumor number $>3$, tumor size $>30 \mathrm{~mm}$, and early recurrence ( $\leq 1$ year) as independent predictors of poor survival after

ASO Author Reflections is a brief invited commentary on the article, "Proposed Definition for Oligometastatic Recurrence in Biliary Tract Cancer Based on Results of Locoregional Treatment: A PropensityScore-Stratified Analysis," Ann Surg Oncol. 2020. https://doi.org/10. 1245/s10434-020-08207-0.

(C) Society of Surgical Oncology 2020

First Received: 27 February 2020;

Published Online: 13 March 2020

S. Seo, MD

e-mail: rutosa@kuhp.kyoto-u.ac.jp recurrence. In the propensity score-stratified analysis, LT was associated with survival benefits in patients representing singleorgan recurrence with 3 or less tumors and late-onset recurrence (>1 year) (median survival time; 48.6 vs. 14.2 months). Given these, we propose that these patients may represent clinically relevant "oligometastatic recurrence" of BTC.

\section{FUTURE}

Our present study defines "oligometastatic recurrence" of BTC and serves novel selection criteria of LT, which can provide long-term survival for patients with recurrent BTC. Yet, to confirm the validity of our proposal, further external validation study would be required. Incorporating LT into treatment strategies for recurrent BTC may contribute to improving prognosis of BTC.

DISCLOSURES The authors report no conflicts of interest.

\section{REFERENCES}

1. Hellman S, Weichselbaum RR. Oligometastases. J Clin Oncol. 1995;13:8-10.

2. Niibe Y, Hayakawa K. Oligometastases and oligo-recurrence: the new era of cancer therapy. Jpn J Clin Oncol. 2010;40:107-11.

3. Valle J, Wasan H, Palmer DH, et al. Cisplatin plus gemcitabine versus gemcitabine for biliary tract cancer. $N$ Engl J Med. 2010;362:1273-81.

4. Takahashi Y, Ebata T, Yokoyama Y, et al. Surgery for recurrent biliary tract cancer: a single-center experience with 74 consecutive resections. Ann Surg. 2015;262:121-9.

5. Park HM, Yun SP, Lee EC, et al. Outcomes for patients with recurrent intrahepatic cholangiocarcinoma after surgery. Ann Surg Oncol. 2016;23(13):4392-400.

6. Morino K, Seo S, Yoh T, et al. Proposed definition for oligometastatic recurrence in biliary tract cancer based on results of locoregional treatment: a propensity-score-stratified analysis. Ann Surg Oncol. 2020. https://doi.org/10.1245/s10434-020-08207-0.

Publisher's Note Springer Nature remains neutral with regard to jurisdictional claims in published maps and institutional affiliations. 